\title{
Can nutritional indicators be used to measure economic development?
}

\author{
BY ELIZABETH DOWLER \\ Centre for Human Nutrition, London School of Hygiene and Tropical Medicine, 2 Taviton Street, \\ London WC1H OBT \\ AND JANE PRYER \\ Centre for Human Nutrition, University of Sheffield, Northern General Hospital, Herries Road, \\ Sheffield S5 7AU
}

The meeting was organized to address theoretical issues in using nutritional indicators to monitor and measure economic development, and to provide a forum for discussing and exchanging practical experience and examples with sympathetic colleagues. About twenty-five participants took part, representing several countries and professional circumstances; the lively round-table discussion which followed the speakers was all too brief.

Elizabeth Dowler, from the Centre for Human Nutrition, London School of Hygiene and Tropical Medicine, began with summary statements from the Overseas Development Administration (ODA) and from other Bi-lateral Aid Agencies, on the potential contribution that human nutrition and food security can make to agency activities; indicators, and the conceptual analysis they provide were described. Some of the operational problems of integrating nutritional concerns, which inevitably cross both disciplinary and internal institutional boundaries, were outlined.

Judith Appleton, working in the Fisheries Division of the Food and Agriculture Organization (but speaking in a personal capacity), continued by highlighting the difficulties other professionals (and some nutritionists!) have in interpreting and actually using traditional 'nutrition' indicators, such as those derived from anthropometric measurements on young children, particularly for monitoring problems of household food security. In addition, her experience in several different circumstances has demonstrated a demand for more exploration within the nutrition profession of participatory methods to define community problems.

Claudia McConnell, from the Department of International Community Health, Liverpool School of Tropical Medicine, gave a lucid and challenging account of participating as a nutritionist among economists in monitoring a rural development programme in Nepal, funded by the ODA. Qualitative and quantitative nutritional indicators were among several used to measure the impact on 'well-being' of household members, and were the principal indicators not to demonstrate improvement over 5 years. Indeed, stunting of children among the poorest groups had increased. She recounted her difficulties in defending these findings, not least because the economists were quick to challenge the sensitivity and significance of the indicators chosen.

Nutritional concepts and techniques are readily used by other disciplines to monitor development and to defend human capital investment. The meeting was welcomed as an opportunity for nutritional scientists themselves to review both the operational and the technical aspects raised thereby. A proposal to pursue these issues at the Dublin meeting in July 1992 was supported with enthusiasm, and an appropriate forum is being arranged. 